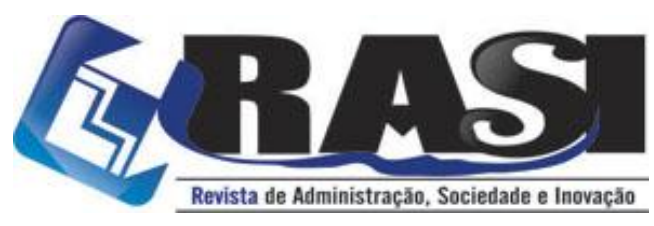

http://www.rasi.vr.uff.br

RASI, Volta Redonda/RJ, v. 6, n. 3, pp. 57-77, set./dez. 2020

\title{
Estilos de Liderança no Tribunal de Contas do Estado do Amazonas.
}

\author{
Caroline de Souza Fernandes (UFAM) - carolinesouza_fernandes@hotmail.com \\ Armando Araújo de Souza Júnior (UFAM) - armandoaraujo@ufam.edu.br \\ Ana Flávia de Moraes Moraes (UFAM) - anaflaviademoraesmoraes@gmail.com
}

\begin{abstract}
RESUMO
O objetivo geral deste estudo foi analisar os estilos de liderança e as circunstâncias que os influenciam, de acordo com o nível dos líderes na estrutura organizacional do Tribunal de Contas do Estado do Amazonas (TCEAM). Para tanto, foi realizada uma pesquisa de natureza quantitativa, cujos dados foram coletados a partir de um questionário aplicado a 30 líderes. A técnica empregada para a interpretação das respostas foi a estatística descritiva com auxílio do software Microsoft Excel. Os resultados constataram que os líderes adaptam seu estilo de liderança, baseados nas variáveis que impactam no dia-a-dia do seu trabalho, sendo essas variáveis presentes no Continuum de liderança de Tannenbaum e Schmidt (1973). Também foi possível averiguar não somente as características do líder, mas também as dos liderados e das demandas de liderança. Apesar dos níveis organizacionais terem seus estilos parecidos, cada nível apresentou uma tendência no estilo de liderança, a qual foi observada por meio, também, do Continuum de liderança de Tannenbaum e Schmidt (1973). Os resultados apresentados neste estudo poderão ser utilizados como referências para novos aprofundamentos no âmbito acadêmico e prático sobre estilos de liderança na Administração Pública.
\end{abstract}

PALAVRAS-CHAVES: Estilos de Liderança; Continuum de Liderança; Administração Pública.

\section{Leadership Styles in the Amazonas States Court of Accounts}

\begin{abstract}
The main objective of the article was to analyze the leadership styles and the circumstances that influence them, according to the level of leaders in the organizational structure of the Amazonas State Court of Auditors. For this purpose, a quantitative research was done, whose data were collected from a questionnaire with 30 leaders. The technique used to interpret the leader's responses was the descriptive statistics with the aid of Microsoft Excel software. The results found that leaders adapt their leadership style based on the variables that impact their daily work. These variables being present in Tannenbaum-Schmidt (1973) Leadership Continuum and through that it was also possible to find out not only the characteristics of the leader, but also those of subordinates and demands. Despite the organizational levels have similar styles, each level showed a tendency in the leadership style, which was observed by analysis using the Tannenbaum-Schmidt (1973) Leadership Continuum. The results presented in this may be used as a reference for further study in the academic and practical field about leadership style in public administration.
\end{abstract}

KEY WORDS: Leadership Style; Leadership Continuum; Public Administration.

\begin{tabular}{c}
\hline $\begin{array}{l}\text { Universidade } \\
\text { Federal } \\
\text { Fluminense }\end{array}$ \\
R. Desembargador Ellis Hermydio Figueira, 783, Bloco A, sl. 218, Aterrado. \\
$27213-415$ - Volta Redonda, RJ - Brasil \\
$\underline{\text { www.uff.br }}$ \\
\hline $\begin{array}{c}\text { Copyright (C) 2020 RASI. Todos os direitos, até mesmo de tradução, são reservados. É } \\
\text { permitido citar parte de artigos sem autorização prévia, desde que seja identificada a fonte. }\end{array}$ \\
\hline
\end{tabular}




\section{Estilos de Liderança no Tribunal de Contas do Estado do Amazonas.}

\section{Introdução}

A liderança é um fenômeno pesquisado por inúmeras áreas acadêmicas, inclusive pela Administração. Calaça e Vizeu (2015) expõem a presença da Administração e a sua influência quanto aos estudos teóricos e empíricos dessa temática.

Dias e Borges (2015) reiteram a relevância do tema ao afirmar que o líder desempenha uma função que exige destaque, visto que a figura do líder potencializa o desempenho da equipe que está ao seu dispor e em decorrência disso o desempenho organizacional é favorecido.

A liderança é a habilidade de convergir as metas e os objetivos dos liderados com os da organização e adaptar seu estilo de liderança às variáveis presentes para alcançar as metas e os objetivos da organização. Para Lacombe (2012) e Moscon (2013), o desempenho do líder se sujeita a inúmeros fatores, ou seja, as características do líder são moldadas às circunstâncias apresentadas a ele, enquanto para Kyrillos e Jung (2015), o exercício da liderança é vinculado à comunicação do líder e liderado, com o intuito do líder compreender os anseios de seus liderados e, assim, desempenhar de maneira correta sua função.

Em função das diversas abordagens associadas ao tema, é imprescindível o estudo dos estilos de liderança, visto que as teorias reducionistas perderam espaço para abordagens mais modernas que conjecturam múltiplas variáveis e foi esse o objetivo geral do trabalho: analisar os estilos de liderança e as circunstâncias que influenciam em cada estilo de liderança de acordo com o nível na estrutura organizacional no Tribunal de Contas do Estado do Amazonas (TCE-AM).

O Tribunal de Contas do Estado do Amazonas, com previsão e competência definidas na Constituição do Estado, configura-se como um órgão de controle externo que auxilia o Poder Legislativo, estadual e municipal, com a missão constitucional de exercer a fiscalização contábil, financeira, orçamentária, operacional e patrimonial do Estado e dos Municípios do Amazonas e das respectivas entidades da administração indireta e entidades controladas, direta ou indiretamente, pelos poderes públicos, conforme competências regidas pela Lei $\mathrm{N}^{\circ}$ 2.423, de 10 de dezembro de 1996.

No que tange a relevância, a presente pesquisa justifica-se, no âmbito teórico, como uma contribuição para a amplificação dos aprendizados referentes à temática em razão da limitação de estudos sobre os estilos de liderança praticados na Administração Pública. No que concerne ao âmbito empírico, os cargos com perfis de liderança são de grande responsabilidade. Dias e Borges (2017) manifestam que alcançar cargos com perfil de liderança na Administração Pública abrange não só responsabilidade, mas também a pressão por resultados e que estudos sobre a temática no Brasil ainda são restritos.

Quanto ao mérito proveniente do trabalho, admite-se o progresso na organização quanto à produtividade, visto que a compreensão do estilo de liderança influirá na adequação do líder com o estilo necessário que beneficiará os processos organizacionais. Para Souza e Dourado (2016), os estudos voltados para o estilo de liderança são de suma importância no âmbito organizacional, já que a adaptação do líder com o estilo adequado de liderança incentiva seus subordinados a produzirem mais.

A sociedade, assim como o âmbito acadêmico e o organizacional, se beneficia de boas lideranças, pois a gestão pública impacta diretamente na sociedade, já que o líder conduz um grupo que está a seu dispor, sendo necessário um bom desenvolvimento profissional para 
transformar o trabalho do servidor público em vantagens sociais. Para Botelho e Pereira (2015), a Administração Pública deve ter qualidade nos serviços prestados à sociedade, já que a sociedade é quem proporciona a execução das atividades desempenhadas pela Administração Pública.

Este artigo está dividido em cinco partes, sendo a introdução a primeira parte, seguida do referencial teórico, onde foi abordado o tema. A metodologia empregada para a realização do estudo é a terceira parte. A quarta parte são os resultados da pesquisa, a quinta parte são as considerações finais, seguida das referências.

\section{Referencial Teórico}

\subsection{Conceitos de Liderança}

A etimologia da palavra líder refere-se a uma pessoa que é o chefe, ou seja, condutor de determinada situação, emitindo a ideia de operador de uma atitude, enquanto liderança é conduzir, imputando uma perspectiva de ação (Cunha, 2012).

É vital ao líder considerar que o entendimento relativo à liderança não é atender somente aos seus desejos ou os da organização que representa, mas também ao coletivo. Para Lacombe e Heilborn (2013), não seria factível o posicionamento de liderança na condição de isolamento das vontades da equipe, em razão do grupo necessitar de estímulos para seguir ideais.

Silva (2014) elucida sobre a relevância do que ele denomina como autoconsciência, onde a trajetória de liderança se torna mais simples a partir da compreensão do líder sobre suas próprias necessidades e metas, pois um líder que não assimila suas questões internas, não terá êxito em perceber quais as necessidades e metas dos seus subordinados.

Liderança é a capacidade do líder de visualizar o futuro da organização e conseguir comunicar suas ideias e metas para seus subordinados. É notória a abundância de conceitos referentes ao tema liderança, visto que a matéria é de suma importância para organizações e para o âmbito acadêmico. Todavia, apesar de existirem diversos conceitos, um elemento destaca-se como ponto comum nas definições apresentadas: os liderados. É requisito para a liderança a presença de um grupo, já que o líder necessita de subordinados para conduzir (Abdalla et al., 2016).

Corroborando, Medeiros e Leone (2017) declaram que, apesar dos estudos pertinentes à liderança não serem novos, ainda assim são fontes de pesquisa e análise por diversos conceitos difundidos, em função da evolução organizacional.

\subsection{Abordagens de Liderança}

Teorias acerca do tema liderança têm sido desenvolvidas desde o século passado. Para Ferreira, Kanaane e Severino (2010), teorias a respeito da temática liderança são encontradas desde o início do século XX e essas teorias argumentam desde os traços de liderança até a teoria da integração.

\subsubsection{Abordagem dos Traços}

O primeiro estudo no campo acadêmico da temática liderança foi através da abordagem clássica da teoria dos traços. Para Silva, Kishore, Reis, Baptista e Medeiros (2013), essa abordagem discorria a respeito de identificações das qualidades e características pessoais, as quais por vezes eram inatas, e, dessa maneira, diferenciava quem tinha traços de líder e quem tinha traços de liderado. Essa teoria, porém, coloca o líder em um espectro generalizado ao restringir os traços de líder apenas aos aspetos pessoais. Para Sant'Anna, 
Campos e Lótfi (2012), estudos referentes aos traços de lideranças inseriam perfis em uma ótica universal, sem ponderar situações e variáveis às quais se submeteriam.

As características que fundamentaram essa teoria foram qualidades consideradas apenas de líderes, ou seja, traços particulares, e através da figura de grandes líderes se traçou um perfil ideal. O objeto de estudo que auxiliou a abordagem foi o mesmo que a enfraqueceu, visto que líderes são pessoas que exercem influência sobre um grupo, e esses não dispõem de um único viés. Sendo assim, à medida que Gandhi era uma personalidade espelho para a abordagem, Hitler também era, já que detinha persuasão sobre determinado grupo. Para Moscon (2013), apesar da teoria ainda ser habitual, suas contradições para com as personalidades citadas como líderes e a complexidade na reprodução das suas características foi um entrave para o êxito da abordagem.

Caravantes, Caravantes e Kloeckner (2010) relatam que a abordagem dos traços analisava diversas características, dentre essas se continha os traços físicos (estatura), intelectuais (inteligência, vocabulário) e sociais (atratividade, autoconfiança) que distinguiam os líderes dos liderados. Entretanto, mediante o surgimento de vários atributos ao perfil de liderança e inúmeras ressalvas quanto à consistência da unificação dessa personalidade, a abordagem teve um declínio no meio acadêmico.

\subsubsection{Abordagem Comportamental}

Diferente da teoria dos traços, a teoria comportamental já não pautava seus estudos em um perfil específico, pois seu foco era no comportamento típico para a liderança. Para Faria e Meneghetti (2011), o foco deixou de serem as características individuais e passou a ser o comportamento do líder, como ele se relaciona com os liderados, como delega tarefas e como motiva os empregados.

A abordagem comportamental teve duas principais análises: a primeira, em Ohio, onde se detectou que o comportamento do líder não era vinculado a apenas uma dimensão, mas várias - enquanto uma dimensão estava relacionada a tarefas ou atividades, a outra estava associada às relações de trabalho, ou seja, às pessoas. Já a segunda é referente aos estudos da Universidade de Michigan. Tais estudos apresentaram o início dos estilos de liderança, um voltado para o empregado e o outro para a produção. Na concepção de Robbins e Judge (2014), os estudos de Ohio e Michigan, apesar de disporem de nomenclaturas distintas, obtiveram resultados semelhantes. Enquanto a pesquisa de Ohio classificou a liderança com foco na relação do líder e do liderado no trabalho, os estudos de Michigan apresentaram o estilo de liderança orientado para o empregado. Também houve convergência quanto à pesquisa de Ohio sobre liderança voltada para as atividades e os estudos de Michigan que tinham a liderança orientada para a produção.

\subsubsection{Abordagem Contingencial ou Situacional}

A teoria contingencial ou situacional compreende um contingente de elementos que abrangem além das características do líder, outras circunstâncias que induzem o estilo de liderança mais adequado. Para Escorsin e Walger (2017), restringir a eficácia do líder aos seus traços ou comportamentos é um equívoco já que, em determinadas situações, a liderança eficaz depende de inúmeras variáveis. Para Soares (2015), apesar dos estudos anteriores à teoria situacional terem relevância, a inexistência de análise das variáveis contingenciais impulsionou estudos que englobam essas circunstâncias.

Segundo Burning, Raso e Paula (2015), a personalidade e a habilidade de adaptá-la às circunstâncias representam a idiossincrasia do líder e, assim como as características do líder, a 
mensuração da maturidade do liderado representa aspectos que afetam a liderança e por último as situações oscilantes.

A primeira teoria da abordagem situacional é a proposta por Fiedler (1967), conhecida por modelo LPC (Least Preferred Coworker, colega de trabalho menos preferido, em tradução livre). Nessa teoria, os estilos de liderança são abordados com a interferência de três variáveis: a relação líder-liderado, estrutura da tarefa e poder de posição. Esse modelo analisa qual o estilo de liderança mais adequado em cada situação. Na concepção de Oliveira (2015), esse modelo expõe que o êxito da liderança está associado à relação das demandas externas para com o estilo de liderança mais adequado e declara que líderes centrados teriam facilidade de desempenho, enquanto os líderes que têm o foco voltado para o relacionamento apenas teriam um desempenho favorável mediante situações moderadas.

O modelo caminho-meta busca expor a importância da liderança, já que é através dela que se alcançam as metas organizacionais e, assim como a teoria de Fiedler, o modelo caminho-meta também classifica o estilo de liderança com foco na tarefa e com foco nas relações. Essa teoria aborda mais um estilo, o participativo. Contudo, o modelo destaca-se por propor a flexibilidade do estilo de liderança. Essa nova teoria expõe que cada situação requer um estilo de liderança, despertando a flexibilidade do líder. Para Caravantes et al. (2010), o modelo precisa avaliar as contingências, tanto do ambiente externo, quanto do grupal, ou seja, devem-se ponderar as circunstâncias influenciadoras e, assim, optar pelo estilo de liderança mais adequado.O modelo caminho-meta apresentou cinco estilos de liderança: desde líder autocrático, com uma subdivisão onde o líder sozinho assume decisões sem consulta e outro que o líder pede informações do grupo, mas continua tomando sozinho as decisões; líder consultivo, também com uma subdivisão em dois e, por fim, o líder participativo, onde a decisão é tomada pelo grupo.

O Continuum de liderança de Tannenbaum e Schmidt (1973) é um modelo da abordagem contingencial ou situacional que versa sobre as variações do comportamento de liderança, que vai desde autocrático até liberal.Os líderes que conferem baixa liberdade aos empregados nas tomadas de decisões denominam-se "liderança autocrática", enquanto os líderes que conferem alta liberdade de decisão aos liderados denominam-se "liberais". Na concepção de Faria e Meneghetti (2011), são três fatores analisados no modelo de Tannenbaum e Schmidt (1973): as forças do gerente, as forças dos liderados e as forças da situação.

\subsubsection{Abordagem da Nova liderança}

Uma nova abordagem denominada como "nova liderança" surgiu e auferiu destaque no meio acadêmico, visto que a perspectiva da figura do líder é modificada., pois, A partir dessa nova abordagem, a visão organizacional converge com os preceitos do líder. Neto, Tanure, Santos e Lima (2012) ressaltam a importância da convergência da visão da organização com os preceitos do líder. Esses declaram que o líder gerencia significados com o intuito de ter êxito na liderança, já que essa não é orientada para apenas um integrante, mas para todos os envolvidos, pois englobam os objetivos e expectativas de todos. Avolio, Walumbwa e Weber (2009) se manifestam quanto à importância das teorias da nova liderança - a teoria transacional e transformacional - as quais nos últimos 20 anos se tornaram as teorias mais pesquisadas.

A primeira teoria da nova abordagem é a liderança carismática, a qual pressupõe que os subordinados, ao optarem por um líder em função de seu carisma, acabam compartilhando ideais, já que a admiração pelo líder induz a busca por semelhança e a história é repleta de 
líderes carismáticos. Baesso, Lopes, Morais e Rodrigues (2017) explanam acerca da liderança carismática e como essa nomenclatura é analisada pela mitologia grega e pelo dogma. Amboni, Lopes, Morais e Rodrigues (2018) afirmam que a identificação de pessoas excepcionais é derivada do carisma.

As duas últimas teorias são a teoria transacional e a transformacional. A teoria transacional refere-se à benesse que será proporcionada ao liderado. Nesse estilo de liderança a influência do líder vem de sua capacidade de proporcionar algo em troca, enquanto a transformacional é voltada para a transformação organizacional. Na concepção de Rezende, Neto e Tanure (2014), as duas teorias têm a relação líder-liderado como alicerce e a motivação é um componente fundamental para a efetividade dessas teorias e é justamente essa motivação que as diferem: uma motiva através de contraprestação, enquanto outra motiva para promover mudanças, ou seja, transformando tanto a organização, quanto o liderado.

\subsection{Estilos de Liderança}

Para Lacombe e Heilborn (2015), o líder, ao escolher qual o estilo de liderança utilizará, precisa averiguar previamente quais são as circunstâncias e os melhores métodos para enfrentá-las.

Hitt, Miller e Colella (2013) defendem que é de responsabilidade do líder conseguir compreender sob quais circunstâncias seu ofício estará submetido e, somente depois dessa análise, escolher qual estilo de liderança é favorável diante do cenário apresentado.

Os três pilares do comportamento organizacional referente ao estilo de liderança são o estilo de liderança autocrático, o democrático e o laissez-faire, onde o estilo autocrático tem a característica de centralizador, o democrático tem a de participativo e o laissez-faire de descentralizador. Ribeiro (2016) esclarece que o líder autocrático atribui somente a si a elaboração das instruções organizacionais, das medidas e formas de desempenhar as incumbências dispostas. Já o líder democrático busca introduzir ao grupo as diretrizes organizacionais e, através dos debates com os liderados, encontrar a melhor maneira de divisão de tarefas, grupos e executar as atividades, tomando a decisão em conjunto. A laissezfaire limita a ação do líder a apenas um auxiliador, ou seja, as decisões são tomadas inteiramente pela equipe e o líder limita a sua atuação a assistir quando for solicitado.

O Continuum de liderança de Tannenbaum e Schmidt (1973) analisa essa variável influenciadora do estilo de liderança. Ele vai da extrema direita à extrema esquerda, onde a primeira é voltada para a liderança autocrática e a segunda refere-se à liderança liberal. Griffin e Moorhead (2015) manifestam-se a respeito do Continuum de liderança e mencionam quais as variáveis presentes nesse modelo para classificar o estilo de liderança, sendo essas as características do líder, dos liderados e as circunstâncias da situação, conforme Figura 1. 
Figura 1. O Continuum de Liderança de Tannenbaum e Schmidt (1973).

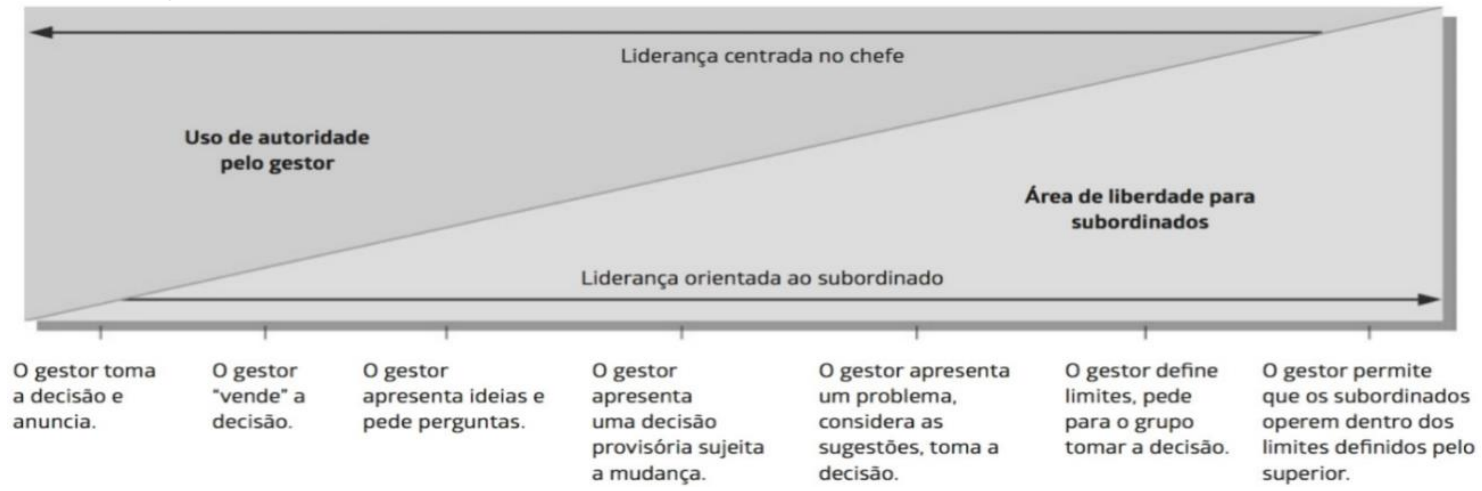

Fonte: Griffin e Moorhead (2015).

Para Caravantes et al. (2010), são três variantes que influenciam na escolha do estilo de liderança, sendo a primeira as que são referentes ao líder, uma vez que esse detém quatro forças internas: os princípios do líder, a confiabilidade para com os liderados, habilidade de liderança e flexibilidade na adaptação do estilo de liderança. A segunda variante é referente aos liderados quanto à alusão à incapacidade de alguns deles tomarem decisões sozinhos, se estão preparados para assumir responsabilidades, se adaptam aos vários estilos de liderança ou sabem tomar decisões quando estão com um líder voltado para o relacionamento. Se existe um problema, esses liderados têm a capacidade ou vontade de solucionar e entendem os objetivos da organização. A última variante é a situação e essa tem quatro circunstâncias: o perfil da organização, o grau de experiência grupal, decisão quanto ao estilo de liderança e o grau de urgência que o líder deve ter quanto às tomadas de decisões.

\subsection{Níveis Organizacionais}

Cada nível da organização exige planejamento para proporcionar uma visão organizacional dos propósitos almejados e é por meio da liderança que se cria a visão futura da organização. Andrade (2016) certificou que o planejamento faz uso de dispositivos normativos com o intuito de auxiliar na concretização das metas e dos objetivos futuros e assistir na deliberação das soluções, sendo necessário o planejamento nos três níveis organizacionais: o estratégico, o tático e o operacional.

O nível estratégico é o mais alto na hierarquia. Os agentes inseridos nesse nível estão vinculados aos cargos mais altos da organização e suas decisões visam a organização como um todo. Para Sertek, Guindani e Martins (2012), os atos que direcionam a trajetória a ser seguida pela organização são tomados pelo nível estratégico e nele se encontram os diretores, gerentes, assessores e consultores. Nogueira (2015) direciona as tomadas de decisões pelo nível estratégico centradas nos anseios externos ao âmbito institucional e, através de suas diretrizes, as quais são de longo prazo, orienta toda organização, ficando a cargo da alta cúpula da organização esse planejamento.

No nível tático ou gerencial as decisões não se aplicam a toda a organização, mas sim a áreas funcionais, departamentos ou divisões, e todas as decisões que são tomadas por esse nível se pautam nas decisões advindas do nível estratégico. Nogueira (2015) afirma que as metas e os objetivos estabelecidos por esse nível são embasados nos escopos propostos pelo nível estratégico, já que esses propósitos são os que guiam toda a organização. Para Sertek et al. (2012), os agentes presentes nesse nível são os coordenadores, chefes, líderes e 
supervisores. Já Caetano e Sampaio (2016) denominam os encargos do nível tático como a otimização de uma área utilizando os comandos preestabelecidos pelo nível hierarquicamente superior.

O último nível é o operacional e esse é subordinado ao nível tático. Na concepção de Rezende (2018), o nível tem a função de atender os propósitos do cotidiano, ou seja, tarefas do seu âmbito e essas têm características específicas e analíticas. Diferente do estratégico que é um planejamento de longo prazo e o tático que é de médio prazo, o operacional é de curto prazo. Para Caetano e Sampaio (2016), o nível operacional está associado à execução dos planos de ações.

\section{Procedimento Metodológico}

O objetivo geral desta pesquisa foi analisar os estilos de liderança e as circunstâncias que influenciam em cada estilo, de acordo com o nível na estrutura organizacional no Tribunal de Contas do Estado do Amazonas (TCE-AM).

O TCE-AM é um órgão da Administração Pública, sendo esse um auxiliador do exercício do controle externo. A função do TCE-AM é controlar os recursos públicos; por meio da fiscalização na aplicação dos recursos públicos pelos gestores, a fim de beneficiar a sociedade amazonense.

A organização tem o quadro de cargos disponível no portal da transparência. Portanto, foi mapeado o quantitativo de cargos de 2019 e, para fins da pesquisa, aglutinaramse os cargos de liderança nos níveis organizacionais, sendo o nível estratégico constituído pela inclusão dos cargos de Auditor, Conselheiro e Procurador de Contas; o nível tático inclui os cargos de Secretário e Diretor, e o nível operacional inclui Chefes de Divisão e Chefes de Departamento.

Optou-se pela abordagem quantitativa tendo em vista a natureza e o objetivo do estudo. Considerando que essa investigação buscou identificar os estilos de liderança predominantes, foi necessária uma análise pautada em números, os quais auxiliaram a compreensão dos dados coletados. Para Mascarenhas (2012), a pesquisa quantitativa baseia-se em artifícios estatísticos, já que essa abordagem busca quantificar os dados coletados para posteriormente analisá-los.

Silva, Lopes e Junior (2014) posicionam a abordagem quantitativa como sendo aquela que requer o conhecimento pelo pesquisador sobre o objeto e suas características.

A abordagem quantitativa foi utilizada nessa pesquisa tanto para quantificar os dados coletados, quanto para correlacionar às variáveis a fim de auxiliar na elucidação dos dados.

Tomando como base o objetivo geral desse estudo, optou-se pela pesquisa descritiva que, na concepção de Mascarenhas (2012, p.47), busca "descrever as características de uma população ou um fenômeno, além de identificar se há relação entre as variáveis analisadas". Em adição, Köche (2016) afirma que a pesquisa descritiva, além de analisar as variáveis presentes no ambiente, também analisa as relações entre essas variáveis.

Optou-se ainda pelo estudo de caso único. No que tange o estudo de caso, Klein, Silva, Machado e Azevedo (2015) referem-se ao objetivo desse procedimento, no qual o propósito é pormenorizar o diagnóstico de uma realidade específica sendo ela de caráter unitário, com o intuito de responder o problema da pesquisa.

No que concerne à natureza da pesquisa, optou-se pela pesquisa aplicada, onde Mascarenhas (2012) afirma que é bastante utilizada na prática, visto que esse estilo busca analisar o problema da pesquisa dentro de um contexto, a fim de solucionar esses problemas. 
Foi escolhido como procedimento o survey, pois se buscou conhecer os comportamentos e atitudes dos pesquisados por meio de um questionário desenvolvido pelas pesquisadoras. Na concepção de Michel (2015), o survey é um artifício que proporciona a correlação entre as variáveis e os dados coletados, propiciando a concepção do comportamento do grupo analisado.

Ao explanar o modelo survey, Klein et al. (2015) expõem a sua relevância, posto que por meio do levantamento de dados de um grupo mediante uma amostra, é possível estabelecer quais as características apresentadas por eles, sendo normalmente empregados questionários para a obtenção das informações necessárias a fim de proporcionar a base para uma futura análise desses dados.

Knechtel (2014) afirma a relevância do questionário nas pesquisas e a necessidade das questões estarem em sincronia, já que a não conexão das questões no questionário pode acarretar interferência de uma questão na outra, ou seja, uma questão pode responder ou induzir a resposta da outra, interferindo na coleta dos dados.

A análise dos dados coletados foi feita mediante a utilização do software Microsoft Excel, visto que o estudo empregou tabelas e gráficos para demonstrar os dados analisados. Martins e Théophilo (2016) endossam que ocorreram inúmeras modificações na análise de dados e passou-se a usar softwares como Excel para análises estatísticas.

A estatística descritiva foi necessária para o resumo dos dados coletados e da descrição desses e, na concepção de Perovano (2016), a análise de dados utilizando a estatística descritiva é pertinente quando o propósito é referente à síntese das informações coletadas mediante a aplicação do questionário na pesquisa de campo, auxiliando na descrição dos dados quantitativos.

A pesquisa bibliográfica foi outro procedimento empregado, pois a investigação utilizou estudos bibliográficos onde inúmeros argumentos de diversos autores são utilizados para corroborar com a base teórica do trabalho. Köche (2016) afirma que a contribuição bibliográfica é um artifício intrínseco em todas as pesquisas, já que o pesquisador usufrui dos conteúdos acadêmicos dispostos e assim fundamentar-se, ou seja, as contribuições teóricas utilizadas pelo pesquisador cooperam na explicação do problema da pesquisa.

O universo total foi de 84 líderes divididos em níveis hierárquicos, onde 20 são do nível estratégico, 26 do nível tático e 38 do nível operacional. A amostra foi pelo critério de acessibilidade, uma vez que não foi possível prever o número exato de líderes do TCE-AM que aceitariam participar da pesquisa. Destaca-se ainda a autorização do TCE-AM para a realização e publicação do estudo.

\section{Resultados e Análises}

A pesquisa se embasou no Continuum de liderança de Tannenbaum e Schmidt (1973). O questionário segue uma lógica, que, a partir da quinta até a oitava questão identificaram-se as características do líder. Enquanto que da nona até a décima terceira questão foram apuradas as características do liderados e a décima quarta e décima quinta referem-se às características das demandas. A seguir os resultados obtidos das questões de $1 \mathrm{a}$ 4 , com as características dos respondentes. 
Tabela 1. Dados dos respondentes

\begin{tabular}{|c|c|c|}
\hline 1. Gênero & Respondentes & $\%$ \\
\hline Masculino & 21 & $70 \%$ \\
\hline Feminino & 9 & $30 \%$ \\
\hline 2. Faixa etária & Respondentes & $\%$ \\
\hline Até 30 anos & 0 & $0 \%$ \\
\hline $31-40$ anos & 5 & $16,7 \%$ \\
\hline $41-50$ anos & 9 & $30 \%$ \\
\hline $51-60$ anos & 13 & $43,3 \%$ \\
\hline Acima de 60 & 3 & $10 \%$ \\
\hline 3. Nível de Escolaridade & Respondentes & $\%$ \\
\hline Ensino Médio & 1 & $3 \%$ \\
\hline Ensino Superior & 3 & $10 \%$ \\
\hline Pós-Graduação Lato Sensu & 22 & $74 \%$ \\
\hline Pós-Graduação Strictu Sensu & 4 & $13 \%$ \\
\hline 4. Cargo & Respondentes & \% por Nível Organizacional \\
\hline Auditor (a) & 0 & \multirow{3}{*}{ 3,3\% do nível estratégico } \\
\hline Conselheiro (a) & 1 & \\
\hline Procurador (a) & 0 & \\
\hline $\begin{array}{c}\text { Diretor } \\
\text { Secretário }\end{array}$ & $\begin{array}{c}11 \\
2\end{array}$ & 43,4\% do nível tático \\
\hline Chefe de departamento & 9 & \multirow{2}{*}{$53,3 \%$ do nível operacional } \\
\hline Chefe de divisão & 7 & \\
\hline
\end{tabular}

Fonte: Dados da pesquisa (2019).

Conforme exposto na Tabela 1, os resultados da pesquisa indicam que de uma amostra de 30 respondentes, $70 \%$ são do gênero masculino e $30 \%$ do gênero feminino. A faixa etária predominante é de 51-60 anos, representando 43,3\% dos respondentes e em seguida com $30 \%$ a faixa etária de 41-50 anos. A respeito do nível de escolaridade existe uma hegemonia de $74 \%$ dos respondentes com pós-graduação lato sensu, seguido de $13 \%$ com pós-graduação strictu sensu. A fim de possibilitar uma análise mais satisfatória, aglutinaramse os cargos nos seus respectivos níveis organizacionais. Sendo a amostra de respondentes de 30 pessoas, 53,3\% representam o nível operacional; 43,4\%, o nível tático, e 3,3\%, o nível estratégico.

Na Tabela 2 é possível observar as características dos líderes, sendo um aspecto muito importante, já que nas teorias situacionais como o Continuum de liderança de Tannenbaum e Schmidt (1973), a idiossincrasia do líder é um ponto que intervém na escolha do estilo de liderança. Caravantes et al. (2010) expõem o que seriam essas características dos líderes, dividindo em: as concepções do líder sobre liderança; a credibilidade dos liderados na avaliação do líder; a capacidade de ser versátil no estilo de liderança e a habilidade de liderar. 
Tabela 2. Características dos líderes

\begin{tabular}{|c|c|c|}
\hline 5. Você conceitua liderança como: & Respondentes & $\%$ \\
\hline $\begin{array}{l}\text { A capacidade de o líder visualizar o futuro da } \\
\text { organização, visão organizacional, e concretizá-la. }\end{array}$ & 10 & $33,3 \%$ \\
\hline $\begin{array}{l}\text { Poder de influência do líder sobre o grupo a sua } \\
\text { disposição para alcançar os objetivos e metas organizacionais. }\end{array}$ & 16 & $53,4 \%$ \\
\hline É a capacidade do líder de inspirar os liderados. & 3 & $10 \%$ \\
\hline $\begin{array}{l}\text { O poder legítimo advindo do cargo que possibilita a } \\
\text { influência sobre os liderados. }\end{array}$ & 1 & $3,3 \%$ \\
\hline 6. Qual a característica você mais se identifica como líder? & Respondentes & $\%$ \\
\hline Amigável & 6 & $20 \%$ \\
\hline Colaborador & 19 & $63,3 \%$ \\
\hline Mentor & 5 & $16,7 \%$ \\
\hline Centralizador & 0 & $0 \%$ \\
\hline $\begin{array}{l}\text { 7. Com que situação você mais se identifica em uma tomada } \\
\text { de decisão? }\end{array}$ & Respondentes & $\%$ \\
\hline $\begin{array}{l}\text { Toma decisão e apenas comunica ao grupo. } \\
\text { Apresenta ao grupo o problema a ser solucionado e }\end{array}$ & 0 & $0 \%$ \\
\hline $\begin{array}{l}\text { discute juntamente com o grupo como solucioná-lo, mas acaba } \\
\text { tomando a decisão sozinho. }\end{array}$ & 5 & $16,7 \%$ \\
\hline $\begin{array}{l}\text { Apresenta ao grupo o problema a ser solucionado, } \\
\text { discute juntamente com o grupo como solucioná-lo e toma a } \\
\text { decisão em conjunto. }\end{array}$ & 24 & $80 \%$ \\
\hline $\begin{array}{l}\text { Apresenta o problema ao grupo e permite que eles } \\
\text { solucionem sem interferir na tomada de decisão. }\end{array}$ & 1 & $3,3 \%$ \\
\hline $\begin{array}{l}\text { 8. Qual das alternativas você se identifica mais com relação } \\
\text { flexibilidade } \\
\text { à } \\
\text { do estilo de liderança: }\end{array}$ & Respondentes & $\%$ \\
\hline $\begin{array}{l}\text { Existem situações em que é preciso adaptar o estilo de } \\
\text { liderança de autocrático para liberal, porém não consigo adaptar } \\
\text { ou tenho dificuldade na adaptação do estilo de liderança. }\end{array}$ & 1 & $3,3 \%$ \\
\hline $\begin{array}{l}\text { Não tenho dificuldade em adaptar o estilo de liderança } \\
\text { quando necessário de autocrático ou liberal para democrático. } \\
\text { Existem situações em que é preciso adaptar o estilo de }\end{array}$ & 10 & $33,3 \%$ \\
\hline $\begin{array}{l}\text { liderança de liberal para autocrático, porém não consigo adaptar } \\
\text { ou tenho dificuldade na adaptação do estilo de liderança. }\end{array}$ & 3 & $10 \%$ \\
\hline $\begin{array}{l}\text { Quando é preciso adaptar o estilo de liderança não } \\
\text { sinto dificuldade. }\end{array}$ & 16 & $53,4 \%$ \\
\hline
\end{tabular}

Fonte: Dados da pesquisa (2019).

De acordo com a Tabela 2, 53,4\% dos respondentes conceituam liderança como o poder de influência do líder sobre o grupo e a sua disposição para alcançar os objetivos e metas organizacionais, seguido por $33,3 \%$ que a veem como a capacidade do líder de visualizar o futuro da organização, visão organizacional, e concretizá-la. Já no tocante à sexta questão, que indaga qual característica você mais se identifica como líder, $63,3 \%$ se classificam como colaborador; seguida de amigável, com $20 \%$. No que concerne à tomada de decisão, $80 \%$ apresenta ao grupo o problema a ser solucionado e discute juntamente com o grupo como solucioná-lo, tomando a decisão em conjunto. Quanto à flexibilidade na adaptação do estilo de liderança, 53,4\% não sentem dificuldade quando é preciso adaptar o estilo de liderança.

Na Tabela 3 apresentam-se os dados quanto às características dos liderados, visto que suas particularidades são os aspectos que interferem na escolha do estilo de liderança. Lacombe e Heilborn (2013) afirmam que as teorias situacionais são sustentadas com base na 
curva de maturidade, ou seja, a escolha do estilo de liderança do líder é pautada na maturidade do grupo a sua disposição. Caravantes et al. (2010) especificam o quanto essa variante está ligada às características dos liderados, sendo segmentada na competência de tomada de decisão pelos liderados, capacidade de responsabilizar-se, adaptação aos vários estilos de líder, compreensão dos objetivos e metas da organização e a disposição em atender as demandas.

Tabela 3. Características dos liderados

\section{Em uma situação de tomada de decisão como o grupo que está a sua Respondentes
disposição reagiria?}

Teriam a capacidade de tomar decisões sozinhos.

Teriam a capacidade de tomar decisões, mas antes consultariam a minha opinião.

Não teriam a capacidade de tomar decisão sem o meu auxílio.

Não teriam a capacidade tomar decisão mesmo com o meu auxílio.

4

$3,3 \%$

24

2

0 Respondentes

26 $6,7 \%$

Aceitam as responsabilidades, pois entendem como um voto de confiança.

Aceitam as responsabilidades, mas não acreditam que tenham a capacidade.

Aceitam as responsabilidades, porém interpretam essa entrega de responsabilidade como forma de transferir o trabalho de terceiros para eles.

Não aceitam assumir as responsabilidades.
1

3

$0 \%$

0 $0 \%$

11. O grupo que está a sua disposição é preparado para mudanças de estilos de liderança?

\section{Respondentes}

Sim, a mudança do estilo de liderança não exerce impacto algum na produtividade ou no relacionamento líder-liderado.

Alguns estão preparados e outros não, mas mesmo os que não estão preparados para a mudança de estilo de liderança não têm sua produtividade afetada e nem o relacionamento líder-liderado.

Não estão preparados, todavia a mudança de estilo de liderança não afeta a produtividade e nem o relacionamento líder-liderado.

Não estão preparados e a mudança do estilo de liderança influencia na produtividade e no relacionamento dos liderados para com o líder.

\begin{tabular}{ll}
5 & $6,7 \%$ \\
23 & $6,7 \%$ \\
1 & $0,3 \%$ \\
1 & $0,3 \%$ \\
\hline
\end{tabular}

\section{Os liderados demonstram entender as metas e os objetivos da organização e Respondentes do setor e demonstram vontade de atender as demandas que chegam?}

Sim, os liderados entendem a importância das metas e dos objetivos da organização e do setor e manifestam vontade em atender às demandas do setor.

Sim, os liderados entendem a importância das metas e dos objetivos da organização e do setor, mas não manifestam vontade em atender às demandas do setor.

Não, os liderados não entendem a importância das metas e dos objetivos da organização e do setor, mas demonstram vontade em atender às demandas do setor.

Não, os liderados não entendem a importância das metas e dos objetivos da organização e do setor e não manifestam vontade em atender às demandas do setor. 


\section{Tabela 3. Características dos liderados (continuação)}

\section{O grupo à sua disposição está preparado para trabalhar em equipe ou é} necessário o seu auxílio para o bom desempenho da equipe?

O grupo à minha disposição não só está preparado para trabalhar em equipe sem o meu auxílio como também demonstra um bom desempenho.

O grupo à minha disposição, apesar de não precisar do meu auxílio, demonstra um bom desempenho.

O grupo à minha disposição não está preparado para trabalhar em equipe sem o meu auxílio, porém com a minha assistência demonstra um bom desempenho.

O grupo à minha disposição não está preparado para trabalhar em equipe sem o meu auxílio e mesmo com a minha assistência não demonstra um bom desempenho.

\section{Respondentes}

\begin{tabular}{cc}
22 & $3,3 \%$ \\
1 & $0,3 \%$ \\
6 & $0 \%$ \\
1 & $0,3 \%$ \\
\hline
\end{tabular}

Fonte: Dados da pesquisa (2019).

A Tabela 3 que apresenta as características dos liderados evidencia a reação dos liderados em uma situação de tomada de decisão, onde uma predominância de $80 \%$ afirmou que os liderados teriam a capacidade de tomar decisões, mas antes, consultariam a opinião do líder. Quanto à reação dos liderados ao assumirem responsabilidade, 86,7\% declaram que os liderados aceitam as responsabilidades, pois entendem como um voto de confiança. Sobre a preparação do grupo à mudança do estilo de liderança do líder, 76,7\% atestam que alguns estão preparados e outros não, mas mesmo os que não estão preparados para o estilo de liderança não têm sua produtividade afetada, tampouco o relacionamento líder-liderado. Acerca do entendimento dos liderados sobre as metas e os objetivos e a vontade de atender as demandas, $86,7 \%$ revelam que tanto o grupo à disposição do líder entende a importância das metas e dos objetivos, quanto manifestam vontade em atender às demandas do setor. Quanto à disposição dos liderados em trabalhar em equipe e o desempenho da equipe, $73,3 \%$ dos respondentes asseguram que o grupo não só está preparado para o trabalho em equipe, como também demonstra um bom desempenho.

A Tabela 4 refere-se a terceira variante que influencia na escolha do estilo de liderança. Para Griffin e Moorhead (2015), as circunstâncias presentes no trabalho influenciam na escolha do estilo de liderança. As questões 14 e 15 tratam sobre as demandas, mais especificamente, sobre o prazo e a origem das demandas.

Tabela 4. Características das demandas

\begin{tabular}{|c|c|c|c|c|c|}
\hline $\begin{array}{l}\text { 14. Quais os prazos } \\
\text { impostos para o } \\
\text { atendimento das } \\
\text { demandas para o } \\
\text { seu setor? }\end{array}$ & Respondentes & $\%$ & $\begin{array}{l}\text { 15. As demandas } \\
\text { encaminhadas ao seu setor } \\
\text { geralmente são de origem: }\end{array}$ & Respondentes & $\%$ \\
\hline Até 15 dias & 9 & $30 \%$ & $\begin{array}{l}\text { Normalmente são de origem } \\
\text { interna. }\end{array}$ & 7 & $23,3 \%$ \\
\hline $15-30$ dias & 19 & $63,4 \%$ & $\begin{array}{l}\text { Normalmente são de origem } \\
\text { externa. }\end{array}$ & 0 & $0 \%$ \\
\hline $31-40$ dias & 1 & $3,3 \%$ & $\begin{array}{l}\text { Tanto interna quanto externa, } \\
\text { porém com maior } \\
\text { predominância interna. }\end{array}$ & 14 & $46,7 \%$ \\
\hline Mais de 40 dias & 1 & $3,3 \%$ & $\begin{array}{l}\text { Tanto interna quanto externa, } \\
\text { porém com maior } \\
\text { predominância externa. }\end{array}$ & 9 & $30 \%$ \\
\hline
\end{tabular}

Fonte: Dados da pesquisa (2019). 
A Tabela 4 demonstra os resultados quanto às características das demandas. A décima quarta questão diz respeito aos prazos impostos para o atendimento das demandas. 63,4\% escolheu 15-30 dias; seguido de 30\% com até 15 dias. Quanto à origem das demandas não houve certo equilíbrio: com $46.7 \%$ tanto interna, quanto externa. Porém, com maior predominância interna; seguido de $30 \%$ tanto interna, quanto externa. Porém, com maior predominância externa; e 23,3\% normalmente são de origem interna.

O propósito no nível estratégico passou a ser averiguar o estilo de liderança do respondente, visto que esta pesquisa analisou os estilos de liderança presentes em cada nível organizacional. As variáveis apresentadas nas Tabelas 2, 3 e 4 serão analisadas de forma particular, ou seja, examinadas e discutidas apenas as repostas do nível estratégico, a fim de determinar qual o estilo de liderança presente no referido nível.

A amostra referente ao nível estratégico foi de somente 1 respondente, representando $3,3 \%$ do total. No que concerne às repostas do nível estratégico em relação às questões de 5 a 8 , as quais são pertinentes às características dos líderes, $100 \%$ das respostas classificam o líder como democrático, visto que a característica que o respondente mais se identifica como líder é a de colaborador. Quando precisa tomar decisão, apesar da palavra final ser do líder, ele, a priori, apresenta ao grupo o problema a ser solucionado e discute juntamente com o grupo como solucionar. Além disso, não tem dificuldade em adaptar o estilo de liderança quando necessário: de autocrático ou liberal, para democrático.

Quanto às questões de 9 a 13 , que são relativas às características dos liderados, foi possível identificar um alto nível de maturidade dos liderados já que, de acordo com as respostas, eles têm capacidade de tomar decisões sozinhos, aceitam responsabilidade, são preparados para mudanças de estilos de liderança, entendem as metas e os objetivos da organização, além de conseguirem trabalhar em equipe sem o auxílio do líder, como também demonstram bom desempenho. As questões 14 e 15 referem-se às características das demandas, onde o prazo é de 15-30 dias e a origem é predominantemente interna.

Identificou-se o estilo de liderança do nível estratégico como sendo democrático, visto que além de ser colaborador, também tem uma equipe preparada, onde não é necessária imposição de um estilo de liderança como o autocrático, pois, a equipe apresenta um bom desempenho sem a necessidade de uma liderança baseada no líder e as demandas são predominantemente de origem interna com um prazo razoável, não forçando outro estilo de liderança para o atendimento da demanda.

Diferente do nível estratégico, o nível tático teve 13 respondentes. Sendo assim, é possível a utilização do gráfico como artifício de auxílio à análise dos dados. O Gráfico 1 tem o propósito de averiguar qual o estilo de liderança do nível tático. Assim, as perguntas apresentadas nas Tabelas 2, 3 e 4 são analisadas no Gráfico 1 de forma particular, a fim de determinar qual o estilo de liderança presente no nível tático. 


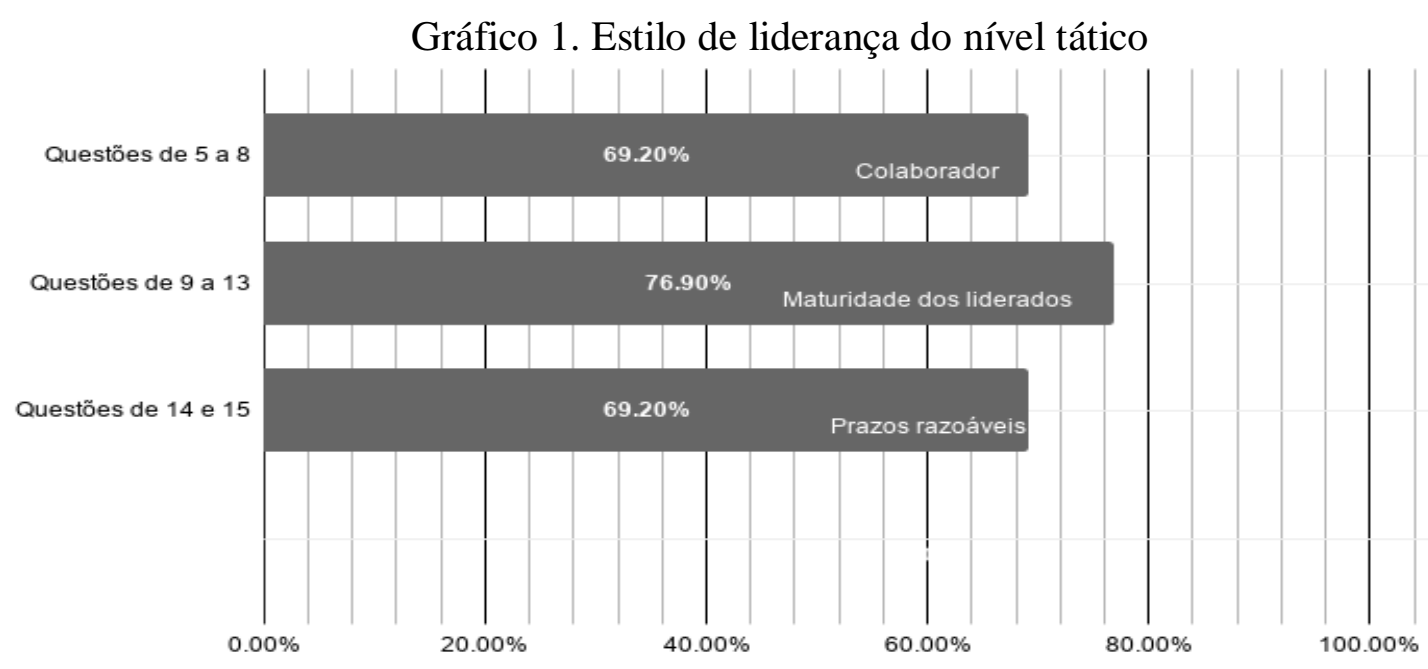

Fonte: Dados da pesquisa (2019).

O nível tático obteve 13 respondentes, o que corresponde a 43,4\% da amostra total. Ao que compete as respostas do nível tático, as questões de 5 a 8 são referentes à primeira variante, ou seja, as características dos líderes. Quanto à conceituação de liderança, 69,2\% dos respondentes classificaram como o poder de influência do líder sobre o grupo à sua disposição para alcançar os objetivos e metas organizacionais. De acordo com Silva et al. (2019), dada a diversidade de concepções, a busca por uma única definição de liderança é inútil e que a definição depende do aspecto específico da liderança de interesse para o indivíduo.

A respeito da característica que os respondentes mais se identificaram como líder, 53,8\% dos respondentes do nível tático escolheram a de colaborador. Quando precisam tomar decisão, 69,2\% afirmam que apresentam ao grupo o problema a ser solucionado e tanto discutem juntamente com o grupo, quanto tomam a decisão em conjunto. Além disso, 30,7\% declararam que não têm dificuldade em adaptar o estilo de liderança, quando necessário, de autocrático ou liberal, para democrático.

Já as questões de 9 a 13 concernem à segunda variante, sendo essa as características dos liderados, onde, a partir dos dados da pesquisa, foi factível a identificação do alto nível de maturidade dos liderados, visto que $76,9 \%$ dos respondentes afirmaram que os liderados teriam a capacidade de tomar decisões, mas consultariam a opinião do líder antes. 76,9\% garantem que os liderados aceitam responsabilidades. Quanto à preparação para a mudança do estilo de liderança, 76,9\% dos respondentes declaram que alguns estão preparados e outros não. Mas, mesmo os que não estão preparados não têm sua produtividade afetada, tampouco relacionamento líder-liderado. $92,3 \%$ dos respondentes certificam que os liderados entendem as metas e os objetivos da organização e manifestam vontade de atender as demandas do setor e $84,6 \%$ confirmam que os liderados conseguem trabalhar em equipe sem o auxílio do líder e também demonstram bom desempenho.

As questões 14 e 15 são referentes à terceira variante: as características das demandas, onde $69,2 \%$ asseguraram que o prazo é de $15-30$ dias e 53,8\% confirmaram que a origem é predominantemente externa.

Diante dos resultados da pesquisa, identifica-se o estilo de liderança do nível tático como sendo democrático, uma vez que a característica do líder evidenciada por meio da pesquisa é de colaborador, o que corresponde à primeira variável. Concomitante, as características dos liderados que correspondem à segunda variante é positiva, ou seja, a alta maturidade do liderados impulsiona para o estilo de liderança escolhido pelo líder, visto que 
além das características internas do líder serem compatíveis com um líder democrático, também detém uma equipe preparada, não necessitando de uma liderança baseada no líder, podendo ser divididas as responsabilidades. Ademais, a terceira variante também é um bom indicador, já que o prazo não impõe a obrigação do líder ser autocrático, pois, apesar das demandas serem predominantemente externas, os prazos são razoáveis.

O Gráfico 2 tem o objetivo de constatar qual o estilo de liderança do nível operacional. As perguntas apresentadas nas Tabelas 2, 3 e 4 foram analisadas no Gráfico 2 de modo particular, a fim de determinar qual o estilo de liderança presente no nível operacional.

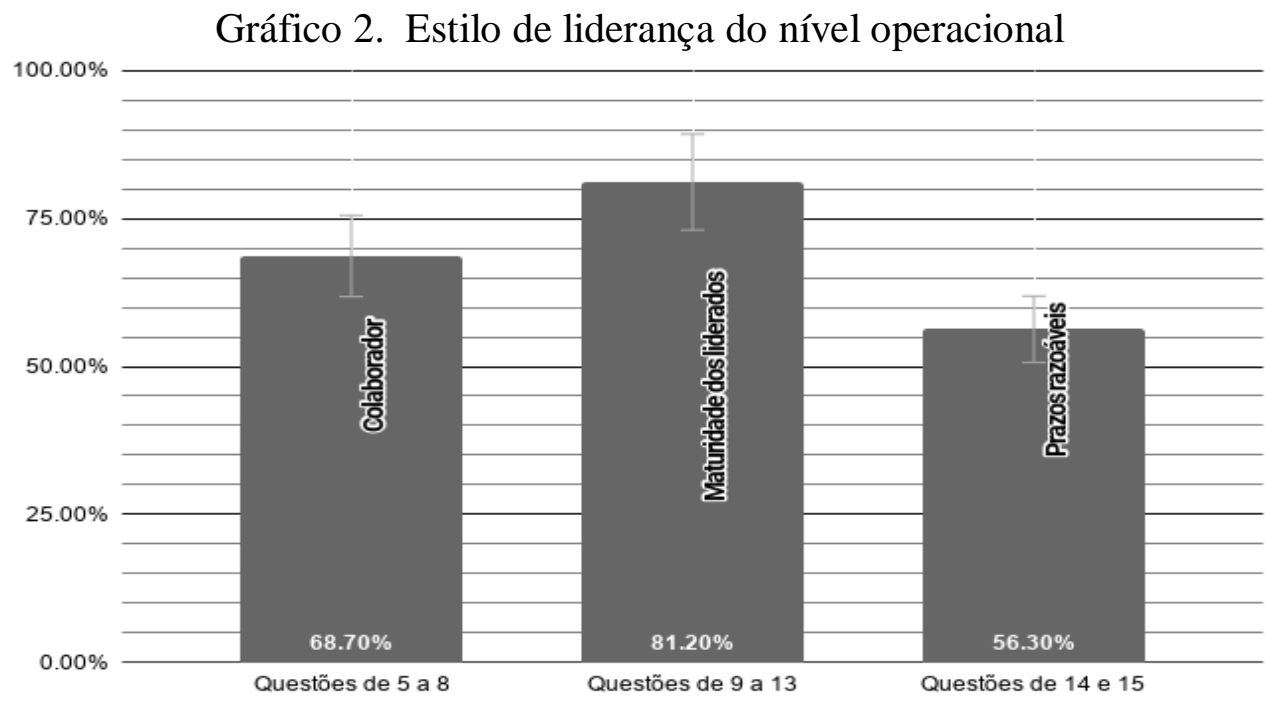

Fonte: Dados da pesquisa (2019).

A amostra referente ao nível operacional é de 16 respondentes, correspondendo a $53,3 \%$ da amostra total. As respostas relativas às questões de 5 a 8 são referentes à primeira variante, ou seja, as características dos líderes, onde $68,7 \%$ se identificou como colaborador; conceituaram liderança como poder de influência do líder sobre o grupo à sua disposição para alcançar os objetivos e metas organizacionais; afirmaram que, em uma tomada de decisão, apresentam ao grupo o problema, tanto discutem as possíveis soluções em conjunto quanto tomam a decisão de forma coletiva e não sentem dificuldade em adaptar o estilo de liderança.

Quanto à conceituação de liderança apresentada pelos respondentes do nível operacional, Cruz et al. (2015) endossam que a influência idealizada é um elemento que reforça o engajamento em comportamentos que nutrem uma relação de confiança e identificação com o líder e diz respeito à capacidade de influenciar seguidores por meio de um ideal.

As questões de 9 a 13 são referentes à segunda variante, a qual trata sobre as características dos liderados, onde $81,2 \%$ dos respondentes asseguram que, em uma tomada de decisão, o grupo à sua disposição teria a capacidade de tomar decisão, mas antes consultaria a opinião do líder. Quando é necessário assumir responsabilidade os liderados aceitam, pois acreditam que seja um voto de confiança. Já quanto à preparação dos liderados para a mudança do estilo de liderança, os respondentes afirmam que, apesar de alguns não estarem preparados, tanto a produtividade quanto o relacionamento líder-liderado não são afetados. Com relação ao entendimento dos liderados sobre as metas e os objetivos da organização e sua vontade de atender às demandas do setor, os respondentes asseguram que os liderados tanto entendem, quanto manifestam vontade de atender às demandas e os 
liderados não só conseguem trabalhar em equipe como também demonstram um bom desempenho.

As questões 14 e 15 referem-se à terceira variante, ou seja, as características das demandas, onde 56,3\% asseguram que o prazo é de $15-30$ dias e 56,2\% declararam que a origem é predominantemente interna.

Com base nos resultados da pesquisa, o estilo de liderança do nível operacional é democrático, visto que ao analisar as três variantes contatou-se que, além do líder ter características democráticas como dividir a responsabilidade de tomar as decisões com o grupo, ser colaborador e se adaptar facilmente ao diversos estilos de liderança, também conta com um grupo com um nível de maturidade alto, podendo assumir responsabilidade e não impulsionando o líder a ter que ser autocrático, já que detém competência para desempenharem suas funções e as demandas não tem um prazo curto, ou seja, existe um tempo razoável possibilitando um estilo de liderança democrático.

\section{Considerações Finais}

O objetivo geral deste artigo foi analisar os estilos de liderança e as circunstâncias que influenciam em cada estilo de liderança, de acordo com o nível da estrutura organizacional no Tribunal de Contas do Estado do Amazonas (TCE-AM).

Neste trabalho buscou-se destacar o Continuum de liderança de Tannenbaum e Schmidt (1973), mais precisamente verificando as três variantes apresentadas no Continuum e traçando o estilo de liderança presente em cada nível organizacional.

Como resultado desta pesquisa, verificou-se que, de 84 líderes presentes no TCEAM, apenas 30 responderam o questionário, sendo divididos nos níveis organizacionais, ou seja, de 20 líderes presentes no nível estratégico, apenas 1 respondeu ao questionário, enquanto de 26 líderes do nível tático, apenas 13 responderam ao questionário e, de 38 líderes presentes no nível operacional, foram obtidos 16 questionários.

Verificou-se ainda que os três níveis organizacionais apresentam o mesmo estilo de liderança. Não obstante, foi factível a diferenciação de cada estilo, já que o Continuum de liderança de Tannenbaum e Schmidt (1973) possibilita a aproximação de um estilo de liderança, mesmo que todos os estilos de liderança apresentados no resultado da pesquisa sejam iguais, tendendo para um dos três estilos presentes no Continuum.

Identificou-se que o nível estratégico, apesar do líder demonstrar um estilo de liderança democrático, apresenta uma característica mais voltada para o estilo autocrático. Todavia, não utiliza esse estilo de liderança, já que o grupo à sua disposição tem alto nível de maturidade e as demandas não forçam outro estilo de liderança. Porém, se o prazo da demanda diminuísse ou a equipe não apresentasse um alto grau de maturidade, esse líder apresentaria um estilo de liderança voltado para o autocrático, ou seja, apesar do líder ser classificado como democrático, indica tendência para o estilo autocrático.

Quanto ao nível tático e operacional, ambos apresentaram o estilo de liderança democrático. Apesar de alguns liderados apresentarem dificuldades na adaptação do estilo de liderança, as outras variantes confirmam que os líderes desses níveis organizacionais detêm o estilo de liderança democrático, já que, mesmo com a presença de equipes que apresentam essas dificuldades, os líderes optaram por um estilo de liderança democrático.

As contribuições obtidas na presente pesquisa contêm limitações em virtude da amostra do nível estratégico, onde, de 20 líderes, apenas 1 respondeu, limitando o estudo a respeito do estilo de liderança do nível estratégico. A partir disso, recomenda-se a ampliação 
da amostra e a utilização do método qualitativo, uma vez que o método quantitativo necessita de um número maior de respondentes para ter um nível de precisão maior.

\section{Referências}

Abdalla, M. M., Botelho, C. F, Brito, P. N., \& Silva, Y. V. (2016). Representação Social da Liderança: análise em uma Organização da Administração Pública Federal. RASI Revista de Administração, Sociedade e Inovação, Rio de Janeiro, 2(1), 52-66.

Amboni, B. F., Lopes, G. S. C., Morais, D. P., \& Rodrigues, A. (2018). Organizational Charismatic Leadership: Levels and Challenges Liderança Carismática: Níveis E Desafios. REUNA, Belo Horizonte, 23(2), 77-95.

Andrade, A. R. (2016). Planejamento estratégico: formulação, implementação e controle. São Paulo: Atlas, $2^{\mathrm{a}}$ edição.

Avolio, B. J., Walumbwa, F. O., \& Weber, T. J. (2009). Leadership: current theories, research, and future directions. Annual Review of Psychology, 60, 421-449.

Baesso, M. F., Lopes, G. S. C., Morais, D. P., \& Rodrigues, A. (2017). A liderança carismática em organizações de saúde do sul de Santa Catarina. Navus, Florianópolis, 7(3), 19-33.

Botelho, L. H. F., \& Pereira, R. M. (2015). Os estilos de liderança e administração pública: o caso de uma Universidade Federal Mineira. Nucleus, Viçosa, 12(2), 39-56.

Burning, C., Raso, C. C., \& Paula, A. (2015). Comportamento organizacional e intraempreendedorismo. Curitiba: Intersaberes.

Caetano, C. I., \& Sampaio, P. P. P. (2016). Planejamento estratégico e administração em segurança. Curitiba: InterSaberes.

Calaça, P. A., \& Vizeu, F.(2015). Revisitando a perspectiva de James MacGregor Burns: qual é a ideia por trás do conceito de liderança transformacional? Cadernos EBAPE.BR, Rio de Janeiro, 13(1), 121-135.

Caravantes, G. R., Caravantes, C. B., \& Kloeckner, M. C. (2010). Administração: Teorias e Processos. São Paulo: Pearson, 6 a edição.

Cruz, A. P. C., Frezatti, F., \& Bido, D. S. (2015). Estilo de Liderança, Controle Gerencial e Inovação: Papel das Alavancas de Controle. Revista de Administração Contemporânea, 19(6), 772-794.

Cunha, A. G. (2012). Dicionário etimológico da língua portuguesa. (4ª ed.). Rio de Janeiro: Lexikon, $4^{\mathrm{a}}$ edição.

Dias, M. A. M. J., \& Borges, R. S. G. E. (2015). Estilos de Liderança e Desempenho de Equipes no Setor Público. REAd - Revista Eletrônica de Administração, Porto Alegre, 80(1), 200-221. 
Dias, M. A. M. J., \& Borges, R. S. G. E. (2017). Performance and Leadership Style: When do Leaders and Followers Disagree? Revista de Administração Mackenzie, São Paulo, 18(2), 104-129.

Escorsin, A. P., \& Walger, C. (2017). Liderança e desenvolvimento de equipes. Curitiba: Intersaberes.

Faria, J. H., \& Meneghetti, F. K. (2011). Liderança e Organizações. Revista de Psicologia, Fortaleza, 2(2).

Ferreira, M. G., Kanaane, S., \& Severino, F. R. G. In: Kanaane, R., Fiel Filho, A., \& Ferreira, M. G.(Org.). (2010). Gestão pública: Planejamento, Processos, Sistemas de Informação e Pessoas. São Paulo: Atlas S. A.

Fiedler, F. E. (1967). A theory of leadership effectiveness. New York: Mc Graw-Hill.

Griffin, R. W., \& Moorhead, G. (2015). Comportamento organizacional: Gestão de Pessoas e Organizações. São Paulo: Cengage Learning, $11^{a}$ edição.

Hitt, M. A., Miller, C. C., \& Colella, A. (2013). Comportamento organizacional. Rio de Janeiro: LTC, $3^{\text {a }}$ edição.

Klein, A. Z., Silva, L. V., Machado, L., \& Azevedo, D. (2015). Metodologia da pesquisa em administração: uma abordagem prática. São Paulo: Atlas.

Knechtel, M. R. (2014). Metodologia da pesquisa em educação: uma abordagem teórico-prática dialogada. Curitiba: InterSaberes.

Köche, J. C. (2016). Fundamentos da metodologia científica: teoria da ciência e iniciação à pesquisa. Petrópolis, RJ: Vozes, $34^{\mathrm{a}}$ edição.

Kyrillos, L., \& Jung, M. (2015). Comunicar para liderar. São Paulo: Contexto.

Lacombe, F. J. M. (2012). Comportamento organizacional fácil. São Paulo: Saraiva.

Lacombe, F. J. M., \& Heilborn, G. L. J. (2013). Administração: princípios e tendências. (São Paulo: Saraiva, $2^{\text {a }}$ edição.

Lacombe, F. J. M., \& Heilborn, G. L. J. (2015). Administração: Princípios e tendências. São Paulo: Saraiva, $3^{a}$ edição.

Martins, G. D. A., \& Theóphilo, C. R. (2016). Metodologia da Investigação Científica para Ciências Socias Aplicadas: com exemplos de formatação e edição de trabalho científico. São Paulo: Atlas, $3^{\text {a }}$ edição.

Mascarenhas, S. A. (2012). Metodologia científica. São Paulo: Pearson Education do Brasil. 
Medeiros, L. S., \& Leone, N. M. C. P. G. (2017). Práticas de liderança na gestão imobiliária. REGE - Revista Gestão, João Pessoa, 24, 210-223.

Michel, M. H. (2015). Metodologia e pesquisa científica em ciências sociais: um guia prático para acompanhamento da disciplina e elaboração de trabalhos monográficos. São Paulo: Atlas, $3^{\text {a }}$ edição.

Moscon, D. C. B. (2013). As relações entre liderança e estabelecimento de vínculos do trabalhador nas organizações. 154 f. Tese (Doutorado em Administração) - Universidade Federal da Bahia, Salvador.

Neto, A. C., Tarune, B., Santos, C. M. M., \& Lima, G. S. (2012). Executivos Brasileiros: Na Contramão do Perfil Deificado da Liderança Transformacional. Revista de Ciências da Administração, Florianópolis, 14(32), 35-49.

Nogueira, C. S. (2015). Planejamento estratégico. São Paulo: Pearson.

Perovano, D. G. (2016). Manual de metodologia da pesquisa científica. Curitiba: InterSaberes.

Oliveira, F. D. S. (2015). Liderança e Gênero: estilos, estereótipos e percepções masculinas e femininas. 142 f. Dissertação (Mestrado em Administração) - Universidade Federal de Pernambuco, Recife.

Rezende, D. A. (2018). Planejamento estratégico público ou privado com inteligência organizacional: guia para projetos em organizações de governo ou de negócios. Curitiba: InterSaberes.

Rezende, F. V., Neto, A. C., \& Tanure, B. (2014). A percepção de executivos e executivas sobre os estilos de liderança. Reuna, Belo Horizonte, 19(4), 107-130.

Ribeiro, A. L. (2016). Teorias da administração. São Paulo: Saraiva, $3^{a}$ edição.

Robbins, S. P., \& Judge, T. A. (2014). Fundamentos do comportamento organizacional. São Paulo: Pearson, $12^{\mathrm{a}}$ edição.

Sant'anna, A. S., Campos, M. S., \& Lótfi, S. (2012). Liderança: o que pensam executivos Brasileiros sobre o tema? RAM - Revista de Administração Mackenzie, São Paulo, 13(6), 48-76.

Sertek, P., Guindani, R. A., \& Martins, T. S. (2012). Administração e planejamento estratégico. Curitiba: InterSaberes, $2^{\mathrm{a}}$ edição.

Silva, D., Lopes, E. L., \& Junior, S. S. B. (2014). Pesquisa Quantitativa: Elementos, Paradigmas e Definições. Revista de Gestão e Secretariado-GeSec, São Paulo, 5(1), 1-18.

Silva, J. G.. (2014). Liderança ética e servidora: Experiência concreta aplicada nos Institutos Federais brasileiros. Florianópolis: Publicação do IFSC. 
Silva, L. M. T., Kishore, A., Reis, G. G., Baptista, L. L., \& Medeiros, C. A. F. (2013). Cultura organizacional e liderança: uma relação possível? Revista Administração São Paulo, 48(1), 34-52.

Silva, P. L., Nunes, S. C., \& Andrade, D. F. (2019). Estilo do líder e comprometimento dos liderados: associando construtos em busca de possíveis relações. Revista Brasileira de Gestão de Negócios, 21(2), 291-311.

Soares, M. T. R. C. (2015). Liderança e desenvolvimento de equipes. São Paulo: Pearson.

Souza, M. J. C., \& Dourado, D. C. P. (2016). Estilo de Liderança: O caso de uma empresa de serviços. Revista Raunp, Pernambuco, 8(2), 34-47.

Tannenbaum, R., \& Schmidt, W. H. (1973). How to choose a Leadership Pattern. Harvard Business Review, p. 166. 